\title{
An Ancient Chinese Treatise on Alchemy.
}

\author{
By Prof. J. R. Partington, M.B.E.
}

$\mathrm{O}^{\mathrm{N}}$ $\mathrm{NE}$ of the early Chinese texts on alchemy is the T's'an T'ung Ch' $i$ of Wei Po Yang, who has been called the father of Chinese alchemy. His treatise has been regarded as the earliest work in the Chinese language which is devoted exclusively to the subject, although it is by no means the earliest Chinese writing which makes mention of alchemy. It shows, in fact, that a definite and extended tradition of alchemy was in existence when it was written, and it mentions several earlier alchemists who are otherwise known, either from their own writings or from notices in Chinese historical works. It seems reasonable to conclude that, for two or three centuries before Wei Po Yang, the Chinese had been engaged in an attempt to transmute base metals into gold, not because gold was intrinsically valuable but because of the supposed magic efficacy of artificial gold in prolonging life. This belief is found also in ancient Egypt ${ }^{1}$ and is no doubt based on the unalterable character of the noble metal. The Chinese believed that an artificial gold could be prepared from cinnabar (mercuric sulphide) which would have a more powerful action than natural gold.

The early Chinese alchemical works attach considerable importance to the synthesis of cinnabar from mercury and sulphur and its resolution into its constituents ${ }^{2}$. These operations also attracted considerable attention among the early Egyptian alchemists, the oldest of whose works, extant in Greek, are supposed to go back to the early centuries of the Christian era ${ }^{3}$, but may be based on texts a century or so earlier. Since Wei Po Yang lived in the second century A.D., and since alchemists are mentioned in Chinese records two or three centuries before this, it is evident that the origins of alchemy in China and in Hellenistic Egypt are practically contemporary. The oldest known works in both cases are of approximately the same date, and in both cases they mention earlier works and traditions-sometimes fabulously early.

It is, therefore, very difficult to decide with our present information whether the origins of alchemy in Egypt and China were independent or not, and, if they were, which was earlier in date. An Arabic origin of Chinese alchemy, on the other hand, although it has been suggested, seems very improbable, since a knowledge of alchemy did not reach the Arabs from Egypt until several centuries after we find alchemy well known in China. A common origin of Chinese and Arabic alchemy is quite possible.

Wei Po Yang was a Taoist philosopher, and the development of alchemy in China was almost certainly closely connected with the later developments of Taoism ${ }^{4}$. He was born in the province of Kiangsu, and in the year 121 A.D. was summoned to the Court, but declined the invitation, having no liking for officialdom. He describes himself in the epilogue of the Ts'an T'ung $C h^{\prime} i$ as "a lowly man who has no love for worldly power, glory, fame or gains", but content to spend his life in peace in a retreat in an unfrequented valley -definitely Taoist sentiments. His work is one of the Taoist classies, and is still read in China. It purports to be a commentary on the old Chinese classic, the Book of Change, but is really a treatise on the preparation of the elixir, or pill of immortality. Chinese works say Wei Po Yang and three disciples went to the mountains to prepare this, and when it was made he tried it on a dog, which died instantly. Wei Po Yang then asked what should be done, whereupon the disciples suggested that he should try it himself. $\mathrm{He}$ did so, saying that it would be a disgrace to live if the preparation of the medicine had failed through lack of concoction, and he also died instantly. One disciple then said: "Our teacher is no common person. He took the medicine and died of it. $\mathrm{He}$ must have done that with some special intention." $\mathrm{He}$ also took the medicine and died. The other two disciples then left to arrange for the burials, but when they had gone Wei Po Yang revived, and resuscitated the disciple and the dog with some of the well-concocted medicine; they all went the way of the immortals, leaving a note with a wood-cutter for the other two disciples.

Wei Po Yang's treatise has been translated by Dr. Lu-Ch'iang Wu and annotated by Prof. Tenney L. Davis ${ }^{5}$, the translation being preceded by an interesting general discussion. It states that the Book of Change, the Taoist doctrines and alchemy are merely three variations of the same thing under different names. It makes use of the early Chinese philosophical conceptions of the Wu-hsing (five elements: wood, earth, water, fire and metal) and Yin-Yang (two contrary principles). The words yin and yang, originally meaning dim or obscure, and bright, respectively, later took on the meanings of numerous pairs of opposites. Thus, yang meant the sun or male principle and yin the moon or female principle, the interaction of which produced the five elements, each identified with a planet. Dr. Wu and Prof. Davis point out that this doctrine of two contraries dominated 
chemistry for a long period, and it may be suspected that it lingers in forms not mentioned by them even at the present day. Dr. Wu suggests, in opposition to generally received opinion, that the notion of yin and yang is not purely Chinese, that it came with the occult doctrines associated with it from some other civilisation, possibly from Babylonia or Egypt, and perhaps alchemy came with it at the same time. "But the search for the elixir of immortality seems to bear no necessary relation to the occult doctrine of the contraries, and we are unwilling to conclude that the two necessarily derive from the same origin." It is suggested that there is a clear and natural affinity between Chinese alchemy and Taoism : if alchemy did not originate out of Taoism, the latter at least "supplied a congenial medium for the growth of alchemical ideas". This theory has, in fact, seemed probable to a number of former investigators ${ }^{2,4}$.

The translation of the Ts'an T'ung Ch'i, which $\mathrm{Wu}$ and Davis divide into sixty-nine chapters, shows that it is, as we should expect, an obscure and mystical work. It contains a number of subtle ideas and is enlivened by a sense of humour and an absence of egotism which contrast favourably with the writings of the Arabic and later European alchemists. Of positive chemical knowledge, such as we frequently find in the Greek alchemists ${ }^{3}$, there is very little, if any. An insistence upon secrecy is found.

As a specimen of the theoretical speculations in the Ts'an T'ung Ch' $i$, the following may suffice :

Chapter 18. "One, knowing the white, should hold firm to the black. For then divine light will come in due course. The white is the essence of gold and the black is the basis of water. The water is the control of the Tao and is one in number. At the beginning yin-yang is black, and with yellow sprouts, the master of the five metals and the river chariot of the north. Hence lead is black on the outside but holds gold flower in its bosom."

Those who are familiar with the Greek chemical texts will find many points of contact between the ideas in them and those of the above and many other passages in the Chinese text. The formation of litharge from lead is probably indicated.

As a specimen of the description of practical operations, the following may be quoted:

Chapter 64. "Above, cooking and distillation take place in the cauldron; below blazes the roaring flame. Before goes the White Tiger leading the way ; following comes the Grey Dragon. The fluttering Scarlet Bird flies the five colours. Encountering ensnaring nets, it is helplessly and immovably pressed down and cries with pathos like a child after its mother. Willy-nilly it is put into the cauldron of hot fluid to the detriment of its feathers. Before half the time has passed,
Dragons appear with rapidity and in great number. The five dazzling colours change incessantly. Turbulently boils the fluid in the furnace. One after another they [the dragons ?] appear to form an array as irregular as a dog's teeth. Stalagmites, which are like midwinter icicles, are spit out horizontally and vertically. Rocky heights of no apparent regularity make their appearance, supporting one another. When yin and yang are properly matched, tranquility prevails."

We have here a fairly clear account, as alchemical literature goes, of some process of solution and crystallisation.

Chapter 66. "White at first and then yellow, it finally becomes red on the outside and on the inside. This is called the first furnace and it is as large as a grain of millet. All this is the work of nature and has nothing to do with untoward doings. It is like the fact that the ch'i (ethereal essence) of the mountains and the waters rises to give clouds which then become rain. Again, it is like the reduction of mud to give dust and the destruction of fire to give earth. The bark of the nieh tree dyes yellow and the lan (indigo) dyes blue; the boiling of hides yields glue, and the ch' $\ddot{u}$ nieh yeast ferments to give liquor. It is easy to get results when the starting materials and the desired products are of the same kind. Otherwise it is very difficult."

Many points of contact between these and other statements in the Chinese treatise and in the Alexandrian Greek treatises can be found, so that the general conclusion of Dr. Wu and Prof. Davis, who do not favour much relation, is scarcely borne out by detailed examination: they eite, in fact, several parallels with Zosimos in the notes and could have eited a good number more. These notes suggest parallels with later works on European alchemy, and there is an index of (transliterated) Chinese words.

Dr. Wu and Prof. Davis are to publish later some alchemical chapters from Ko Hung, a celebrated Chinese Taoist philosopher and alchemist of the fourth century, and the history of chemistry will be enriched by their work. The translation of these early texts is a difficult task, from which previous sinologists have turned away in something like despair, but there is nothing like making a start. Criticism and improvement can follow this, but they do not precede it.

\footnotetext{
'Partington, "Origins and Development of Applied Chemistry", London : Longmans, Green and Co., Ltd., 1935. 23, 181.

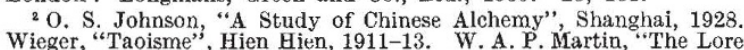
Wieger, "Taoisme", Hien Hien,
of Cathay", New York, 1901.

${ }^{3}$ Berthelot, "Collection des Alchimistes Grecs", 3 vols., Paris, 1888. F. Sherwood Taylor, "A Survey of Greek Alchemy", J. Hellenic Studies, 50, 109-139; 1930.

- Edkins, Trans. China Branch Roy. Asiat. Soc., Hong Kong, 1855, pt. 5, 83-89; a valuable paper; cf. Partington, NATURE, 120, 158 ; 1927. Johnson, ref. 2, curiously omits to mention it.

'Lu-Chi'ang Wu and T. L. Davis, Isis, 18, 210-289; 1932. Davis, Scientific Monthly, Sept. 1930 .
} 